\title{
The prevalence and risk factors of stroke in patients with chronic schizophrenia
}

This article was published in the following Dove Press journal:

Neuropsychiatric Disease and Treatment

9 May 2016

Number of times this article has been viewed

\author{
Ying Liang' \\ Jian Huang' \\ Jingbin $\operatorname{Tian}^{2}$ \\ Yuanyuan $\mathrm{Cao}^{2}$ \\ Guoling Zhang ${ }^{2}$ \\ Chungang Wang ${ }^{2}$ \\ Ying $\mathrm{Cao}^{2}$ \\ Jianrong $\mathrm{Li}^{2}$ \\ 'National Clinical Research Center \\ for Mental Disorders, Peking \\ University Sixth Hospital, Institute \\ of Mental Health, Key Laboratory of \\ Mental Health, Ministry of Health, \\ Peking University, ${ }^{2}$ Changping \\ Traditional Chinese Medicine Hospital, \\ Beijing, People's Republic of China
}

Correspondence: Ying Liang National Clinical Reseach Center for Mental Disorders, Peking University Sixth Hospital, Institute of Mental Health, Ministry of Health, Peking University, Beijing, Haidian District, Huayuanbeilu 5I, I0019I, People's Republic of China Email liangying1980@bjmu.edu.cn
Objective: To investigate the stroke risk and risk factors in patients with chronic schizophrenia.

Patients and methods: This study was a large-sample, cross-sectional survey. A total of 363 patients with chronic schizophrenia were selected from the Changping Traditional Chinese Medicine Hospital, Beijing, in August 2014. The patients were divided into either stroke group or control group based on the presence of stroke. Clinical evaluation included positive and negative syndrome scale assessment and a detailed questionnaire to collect the general information and disease-related conditions.

Results: The prevalence of stroke was $16.5 \%$ (60 cases). Stroke and control groups showed a significant difference in age, sex, smoking, combined medication, doses, negative factor score in positive and negative syndrome scale, body mass index, waist circumference, and systolic blood pressure. Multivariate analysis showed that a number of factors are significantly related to stroke, including age, sex, smoking, combined medication, doses, body mass index, and systolic blood pressure.

Conclusion: The prevalence of stroke is relatively higher in Chinese patients with chronic schizophrenia. Chronic schizophrenia patients are more likely to suffer from stroke; meanwhile, a number of risk factors were identified, including old age, female sex, smoking history, combined medication with a variety of drugs, high doses, obesity, and high blood pressure.

Keywords: schizophrenia, stroke, risk, risk factors

\section{Introduction}

The risk of premature death in schizophrenia patients is two to three times that in the general population, resulting in a reduction in life expectancy of 15-20 years. It is well known that cerebrovascular diseases are one of the leading causes of premature death in schizophrenia patients. ${ }^{1,2}$ In recent years, more and more scholars began to focus on the association of cerebrovascular diseases in patients with schizophrenia, and they found that the prevalence of such cerebrovascular diseases was significantly higher than that in the general population. ${ }^{3,4}$

At present, stroke is the second leading cause of death in the People's Republic of China, as well as a major cause of disability. There is an annual increase of $\sim 2$ million patients who are newly diagnosed with stroke, which brings a heavy burden to both society and individuals. However, till now, only few studies in Mainland China have focused on the stroke-associated issues in patients with schizophrenia.

In this study, a large-sample, cross-sectional survey was conducted, aiming at 1) exploring the stroke risk in patients with chronic schizophrenia and 2) investigating the risk factors for stroke in patients with chronic schizophrenia. 


\section{Patients and methods Subjects}

Patients with schizophrenia admitted to the psychiatric ward of Changping Traditional Chinese Medicine Hospital in August 2014 were included in this study. Inclusion criteria were 1) meeting the diagnostic criteria for schizophrenia by International Classification of Mental and Behavioral Disorders Diagnostic Criteria (ICD-10) ${ }^{5}$ ) with disease duration $\geq 10$ years. In addition, stroke was confirmed by the diagnostic criteria for cerebrovascular disease classification revised by Chinese Academy of Neurology and Chinese Academy of Neurosurgery in $1995 .{ }^{6}$

The study protocol and written informed consent were in accordance with the Guideline for Good Clinical Practice of the International Conference on Harmonisation, ${ }^{7}$ which was approved by the Ethics Committee of Peking University, Institute of Mental Health. Prior to the enrollment, written informed consent was obtained from the subjects or their legal guardians. A total of 704 cases of subjects were screened, of which 363 cases were qualified for our study.

\section{Clinical assessment}

Positive and negative syndrome scale (PANSS) was measured, ${ }^{8}$ which is an evaluation scale of 30 disparate items scored from 1 to 7 for psychopathological symptoms. A total of three subscores (positive, negative, and general psychopathology) were obtained with this evaluation tool. A questionnaire was used for collecting the general information and disease conditions, including age, sex, date of birth, education level, ethnicity, marital status, age of onset, disease duration, previous disease history, medication history, family history of cerebrovascular disease, smoking and drinking history, body mass index, fasting glucose levels, lipid levels, and current medication list; in addition, the current dose of antipsychotic was converted to equivalent doses of chlorpromazine. ${ }^{9}$

\section{Statistical methods}

Data were analyzed using the SPSS 17.0 statistical package for Windows. The comparison between the two groups with regard to sociodemographic and clinical characteristics was performed by independent samples $t$-test for data of normal distribution, by the Mann-Whitney $U$-test for continuous variables, and by the chi-square test for categorical variables. Multiple logistic regression analysis was carried out to adjust for relevant covariates and to determine the risk factors of stroke. The one-sample Kolmogorov-Smirnov test was used to check the normality of distributions for continuous variables. Level of significance was set at 0.05 (two-tailed).

\section{Results}

\section{Stroke risk}

Among the 363 patients with chronic schizophrenia, the prevalence of stroke was $16.5 \%$ (60 cases); the majority of these stroke patients had cerebral infarction (59 cases), whereas one case had cerebral hemorrhage. The prevalence rates of stroke were $11.2 \%(20 / 178)$ and $21.6 \%(40 / 185)$ in male and female patients, respectively.

\section{Risk factors for stroke}

Patients were divided into stroke group and control group according to the presence of stroke. The following information was significantly different between the two groups, such as age, sex, smoking, combined medication, doses, negative factor score in PANSS, body mass index, waist circumference, and systolic blood pressure (Table 1). Multivariate analysis found that age, sex, smoking, combined medication, doses, body mass index, and systolic blood pressure were significantly related to stroke (Table 2).

\section{Discussion}

To our knowledge, this is the first study in Mainland China that investigates the prevalence and risk factors of stroke in the patients with schizophrenia. We found that $16.5 \%$ of patients with chronic schizophrenia had stroke, and this value was significantly higher than that reported by Taiwan $(1.7 \%)^{10}$ and Canada $(7.9 \%),{ }^{3}$ which might probably be due to the fact that the schizophrenia patients included in our study were much older and their disease were more heavy, while with longer disease duration. However, it could also be related to the recent changes in disease spectrum in Mainland China. A previous study had shown that the stroke prevalence in the community residents of Beijing was $4.8 \%,{ }^{11}$ significantly higher than the figures reported by Taiwan $(1.2 \%)^{10}$ and Canada (4.3\%). ${ }^{3}$ With the recent improvement of socioeconomic conditions of Mainland China, the life patterns and diet structures have great changes; therefore, obesity, hypertension, hyperlipidemia, and other chronic diseases have become a major threat to the health of residents, while the prevalence of cerebrovascular disease was also increased every year. ${ }^{11}$ However, what is consistent with the previous findings is that schizophrenia could greatly enhance the risk of stroke, ${ }^{3,10,12}$ suggesting that the psychiatric researchers in Mainland China should pay special attention to the issues of stroke in patients with chronic schizophrenia. 
Table I Comparison of general population information and clinical data between the stroke group and control group

\begin{tabular}{|c|c|c|c|c|c|c|c|}
\hline & \multicolumn{2}{|c|}{$\begin{array}{l}\text { Whole sample } \\
(n=363)\end{array}$} & \multicolumn{2}{|c|}{$\begin{array}{l}\text { Stroke group } \\
(n=60)\end{array}$} & \multicolumn{2}{|c|}{$\begin{array}{l}\text { Control group } \\
(n=303)\end{array}$} & \multirow[t]{2}{*}{$P$-value } \\
\hline & $\mathbf{N}$ & $\%$ & $\mathbf{N}$ & $\%$ & $\mathbf{N}$ & $\%$ & \\
\hline Age & & & & & & & 0.00 \\
\hline$\geq 65$ years & 106 & 29.2 & 34 & 56.7 & 72 & 2.8 & \\
\hline Sex (female) & 185 & 60.0 & 40 & 66.7 & 145 & 47.8 & 0.01 \\
\hline Duration of illness in schizophrenia (years) & & & & & & & 0.10 \\
\hline$<20$ & 40 & 11.0 & 4 & 6.7 & 36 & 11.9 & \\
\hline $20-30$ & 114 & 31.4 & 14 & 23.3 & 100 & 33.0 & \\
\hline$>30$ & 209 & 57.6 & 42 & 70.0 & 167 & 55.1 & \\
\hline Family history of cerebrovascular disease & 142 & 39.1 & 25 & 41.7 & 117 & 38.6 & 0.66 \\
\hline History of smoking & 61 & 16.8 & 22 & 36.7 & 39 & 12.9 & 0.00 \\
\hline History of alcohol abuse & 39 & 10.7 & 10 & 16.7 & 29 & 9.6 & 0.11 \\
\hline Antipsychotic polypharmacy & 208 & 57.3 & 49 & 81.7 & 159 & 52.5 & 0.00 \\
\hline Type of APs & & & & & & & 0.16 \\
\hline Only typical APs & 25 & 6.9 & I & 1.7 & 24 & 7.9 & \\
\hline Only atypical APs & 293 & 80.7 & 53 & 88.3 & 240 & 79.2 & \\
\hline Combination & 45 & 12.4 & 6 & 10.0 & 39 & 12.9 & \\
\hline Doses of antipsychotic drugs (CPZ) & & & & & & & 0.00 \\
\hline$<300 \mathrm{mg}$ & 89 & 6.7 & 4 & 6.7 & 85 & 28.1 & \\
\hline $300-600 \mathrm{mg}$ & 118 & 30.0 & 18 & 30.0 & 110 & 36.3 & \\
\hline \multirow[t]{2}{*}{$>600 \mathrm{mg}$} & 146 & 63.3 & 38 & 63.3 & 108 & 35.6 & \\
\hline & Mean & SD & Mean & SD & Mean & SD & $P$-value \\
\hline PANSS score & 49.3 & 13.7 & 52.0 & 14.7 & 48.8 & 13.5 & 0.10 \\
\hline PANSS positive factors & 12.1 & 5.1 & 11.7 & 4.5 & 12.2 & 5.2 & 0.54 \\
\hline PANSS negative factors & 13.1 & 5.8 & 14.7 & 5.3 & 12.8 & 5.8 & 0.02 \\
\hline Body mass index $\left(\mathrm{kg} / \mathrm{m}^{2}\right)$ & 25.5 & 6.2 & 28.2 & 3.3 & 25.0 & 6.5 & 0.00 \\
\hline Waist circumference (cm) & 81.9 & 13.1 & 85.0 & 8.7 & 82.0 & 13.5 & 0.04 \\
\hline Systolic blood pressure $(\mathrm{mmHg})$ & 118.5 & 9.5 & 122.2 & 14.4 & 117.8 & 8.6 & 0.01 \\
\hline Diastolic blood pressure $(\mathrm{mmHg})$ & 74.6 & 6.1 & 74.9 & 7.4 & 74.5 & 5.8 & 0.69 \\
\hline Fasting glucose levels (mmol/L) & 4.8 & 1.4 & 4.9 & 1.6 & 4.7 & 1.3 & 0.41 \\
\hline Total cholesterol (mmol/L) & 3.9 & I.I & 4.1 & 1.6 & 3.9 & 1.0 & 0.29 \\
\hline Triglyceride (mmol/L) & 1.5 & 0.9 & 1.5 & 0.9 & 1.4 & 0.9 & 0.79 \\
\hline
\end{tabular}

Notes: Results are in response to an independent $t$-test and where appropriate the chi-square test. $P$-values were considered significant at the $\alpha 0.05$ level.

Abbreviations: APs, antipsychotics; PANSS, positive and negative syndrome scale; CPZ, chlorpromazine.

Our study found that the prevalence of stroke in female patients with schizophrenia is much higher than that of male patients, which is consistent with two previous studies conducted in Taiwan; ${ }^{10,12}$ however, it was contrary to the

Table 2 Multivariate analysis of risk factors for stroke

\begin{tabular}{|c|c|c|c|}
\hline Factors & P-value & Odds ratio & $95 \% \mathrm{Cl}$ \\
\hline Aged $\geq 65$ years & 0.003 & 2.87 & I.42-5.79 \\
\hline Sex (female) & 0.016 & 2.35 & I. $17-4.70$ \\
\hline History of smoking & 0.001 & 3.72 & $1.76-7.88$ \\
\hline Antipsychotic polypharmacy & 0.005 & 3.06 & $1.4 \mid-6.66$ \\
\hline Drug doses & 0.001 & - & - \\
\hline \multicolumn{4}{|l|}{$<300 \mathrm{mg}$} \\
\hline $300-600 \mathrm{mg}$ & 0.039 & 3.68 & $1.07-12.68$ \\
\hline$>600 \mathrm{mg}$ & 0.000 & 8.39 & $2.55-27.62$ \\
\hline Body mass index $\left(\mathrm{kg} / \mathrm{m}^{2}\right)$ & 0.014 & 1.07 & $1.01-1.12$ \\
\hline Systolic blood pressure $(\mathrm{mmHg})$ & 0.004 & 1.05 & $1.01-1.08$ \\
\hline
\end{tabular}

Notes: Results are in response to a multiple logistic regression analysis. $P$-values were considered significant at the $\alpha 0.05$ level. findings in general population, ${ }^{13}$ which might be because obesity and metabolic syndrome are more commonly seen in female patients with schizophrenia. ${ }^{14}$

This study shows that stroke risk in elderly patients was significantly higher, similar to the findings observed in the general population; the reason might be that such aging population is closely associated with hypertension, hyperlipidemia, hypercoagulable state and cytotoxicity. Elderly patients with schizophrenia should obviously be viewed as a major focus in the prevention of stroke. ${ }^{15}$

Compared with the nonstroke patients, stroke patients with schizophrenia have more risk factors such as obesity, smoking, and high blood pressure, which is in line with the findings in the general population. ${ }^{11}$ Interestingly, our study did not find that the involvement of family history of cerebrovascular disease could have a significant effect on stroke patients with schizophrenia, suggesting that compared 
to genetic history, environmental factors could play a larger part in stroke onset of the patients with schizophrenia.

This study shows that a larger number of schizophrenia patients diagnosed with stroke are more likely to use the combination therapy of antipsychotics, with higher doses, which has not been reported in previous studies. It should be noted that combination therapy using multiple drugs often needs larger doses, with more prominent adverse reaction. ${ }^{16}$ In particular, it has been widely proven that antipsychotics cause issues such as weight gain, obesity, and metabolic syndrome, ${ }^{17}$ which are clear risk factors for stroke.

\section{Conclusion}

Patients with chronic schizophrenia have a high risk of stroke in Chinese population. A number of risk factors were associated with stroke in chronic schizophrenia, including old age, female sex, smoking history, combined medication with a variety of drugs, high doses, obesity, and high blood pressure. Hence, special attention should be paid by clinical psychiatrists.

\section{Acknowledgment}

This work was supported by Beijing High School Youth Talent Foundation Project Plan project (no YETP0073).

\section{Disclosure}

The authors report no conflicts of interest in this work.

\section{References}

1. Hennekens $\mathrm{CH}$. Increasing global burden of cardiovascular disease in general populations and patients with schizophrenia. J Clin Psychiatry. 2007;68(Suppl 4):4-7.

2. Thornicroft G. Physical health disparities and mental illness: the scandal of premature mortality. Br J Psychiatry. 2011;199(6):441-442.
3. Curkendall SM, Mo J, Glasser DB, Rose Stang M, Jones JK. Cardiovascular disease in patients with schizophrenia in Saskatchewan, Canada. J Clin Psychiatry. 2004;65(5):715-720.

4. Crump C, Winkleby MA, Sundquist K, Sundquist J. Comorbidities and mortality in persons with schizophrenia: a Swedish national cohort study. Am J Psychiatry. 2013;170(3):324-333.

5. Fan XD, Wang XD, Yu X, et al. World Health Organization ICD-10 Classification of Mental and Behavioral Disorder: Clinical Descriptions and Diagnostic Criteria. Beijing: People's Health Press; 1993:72-79. [Translated in Chinese].

6. Chinese Journal of Neurology, Chinese Academy of Neurology Surgery. Diagnostic criteria of all types of cerebrovascular disease (1995). $J$ Clin Exp Med. 2013;12(7):559. [in Chinese].

7. Tian SL. Drug Clinical Trials and GCP. Beijing: Peking University Medical Press; 2003:91-101. [in Chinese].

8. He YL, Zhang MY. Positive and negative syndrome scale and its application. Clin J Psychiatry. 1997;7(6):353-355. [in Chinese].

9. Woods SW. Chlorpromazine equivalent doses for the newer atypical antipsychotics. J Clin Psychiatry. 2003;64(6):663-667.

10. Tsai KY, Lee CC, Chou YM, Su CY, Chou FH. The incidence and relative risk of stroke in patients with schizophrenia: a five-year follow-up study. Schizophr Res. 2012;138(1):41-47.

11. Zhang F, Yu JM, Ding RJ. Analysis of risk and cognition status of stroke in residents of Beijing. Chin J Intern Med. 2011;31(2):116-118. [in Chinese].

12. Lin HC, Hsiao FH, Pfeiffer S, Hwang YT, Lee HC. An increased risk of stroke among young schizophrenia patients. Schizophr Res. 2008;101(1-3):234-241.

13. Feng LZ, Zhang QH, Chen XQ, et al. Study on risk factors of ischemic stroke among young patients. Beijing Med. 1999;21(4):216-217. [in Chinese].

14. Evoy JP, Meyer JM, Goff DC, et al. Prevalence of the metabolic syndrome in patients with schizophrenia: baseline results from the clinical antipsychotic trials of intervention effectiveness (CATIE) schizophrenia trial and comparison with national estimates from NHANES III. Schizophr Res. 2005;80(1):19-32.

15. Li DY. Risk factors of cerebrovascular disease. J Lanzhou Univ. 2002;38(3):98-102.

16. Sim K, Su A, Fujii S, et al. Antipsychotic polypharmacy in patients with schizophrenia: a multicentre comparative study in East Asia. Br J Clin Pharmacol. 2004;58(2):178-183.

17. Newcomer JW. Second-generation (atypical) antipsychotics and metabolic effects: a comprehensive literature review. CNS Drugs. 2005;19(Suppl 1):1-93.
Neuropsychiatric Disease and Treatment

\section{Publish your work in this journal}

Neuropsychiatric Disease and Treatment is an international, peerreviewed journal of clinical therapeutics and pharmacology focusing on concise rapid reporting of clinical or pre-clinical studies on a range of neuropsychiatric and neurological disorders. This journal is indexed on PubMed Central, the 'PsycINFO' database and CAS,

\section{Dovepress}

and is the official journal of The International Neuropsychiatric Association (INA). The manuscript management system is completely online and includes a very quick and fair peer-review system, which is all easy to use. Visit http://www.dovepress.com/testimonials.php to read real quotes from published authors. 